\title{
KINERJA PIPA RESAPAN SEBAGAI PENDUKUNG KONSERVASI AIR
}

\author{
Edy Susilo ${ }^{\star}$, Diah Setyati Budiningrum² \\ 1.2) Jurusan Teknik Sipil, Fakultas Teknik, Universitas Semarang \\ Jalan Arteri Sukarno Hatta - Tlogosari - Semarang \\ e-mail :123edysusilo@gmail.com
}

\begin{abstract}
Changes in land use that make the ground surface more impervious cause a decrease in groundwater infiltration and an increase in surface runoff. Various attempts made by using infiltration wells and bio pores have not yet achieved the expected results. A horizontal recharge pipe is expected to be one solution to overcome these problems. By using a horizontal recharge pipe with a length of $2 \mathrm{~m}$ to $7 \mathrm{~m}$, a diameter of $10 \mathrm{~cm}$, the effect of variable length on the discharge of water infiltration in the ground is obtained. Water infiltration with a horizontal recharge pipe diameter of $30 \mathrm{~cm}$, length $\mathrm{Lcm}$, wall hole ratio of 0.028 , and water pressure height of $\mathrm{H} \mathrm{cm}$ in clay-type soil with permeability of $7.09 \times 10^{-6} \mathrm{~cm} /$ second expressed by the equation $Q=0.00019 \times L^{0,913} \times H^{2.3965}$. Flood discharge in a watershed is calculated using the Rational formula and horizontal recharge pipe requirements can be obtained using graphs. The use of horizontal recharge pipes with other specifications and different types of soil needs research development. The results of this study are expected to be used to maintain water conservation while handling flood problems.
\end{abstract}

Keywords: horizontal recharge pipe; conservation; flood.

\begin{abstract}
ABSTRAK
Perubahan tataguna lahan yang menjadikan permukaan tanah semakin kedap menyebabkan penurunan infiltrasi air tanah dan peningkatan debit aliran permukaan. Berbagai upaya yang dilakukan dengan menggunakan sumur resapan dan biopori belum mencapai hasil yang diharapkan. Pipa resapan horisontal diharapkan menjadi salah satu solusi untuk mengatasi permasalahan tersebut. Dengan menggunakan pipa horisontal dinding berlubang panjang $2 \mathrm{~m}$ sampai $7 \mathrm{~m}$ diameter $10 \mathrm{~cm}$ diperoleh pengaruh variabel panjang terhadap debit resapan air di dalam tanah. Debit resapan air dengan pipa horisontal diameter $30 \mathrm{~cm}$, panjang $\mathrm{L} \mathrm{cm}$, rasio lubang dinding 0.028, dan tinggi tekan air $\mathrm{H} \mathrm{cm}$ pada tanah jenis clay dengan permeabilitas $7.09 \times 10^{-6} \mathrm{~cm} /$ detik dinyatakan dengan persamaan $\mathrm{Q}=0.00019 \times \mathrm{L}^{0,913} \mathrm{xH}^{2.3965}$. Debit banjir pada sebuah DAS dihitung dengan rumus Rasional dan kebutuhan pipa resapan horisontal dapat diperoleh dengan menggunakan grafik. Penggunaan pipa resapan horisontal dengan spesifikasi lain dan jenis tanah yang berbeda perlu dilakukan pengembangan penelitian. Hasil penelitian ini diharapkan dapat digunakan untuk memelihara konservasi air sekaligus penangan permasalahan banjir
\end{abstract}


Kata kunci: pipa resapan horisontal, konservasi, banjir

\section{PENDAHULUAN}

Kekeringan dan penurunan permukaan air tanah yang diikuti oleh perembesan air laut di daerah pantai menjadi permasalahan di beberapa wilayah. Menurut Rahman (2008) permukaan-permukaan tanah kedap air yang bertambah dalam suatu Daerah aliran sungai (DAS) akan berpengaruh pada volume air yang tersedia di dalam tanah dan aliran air permukaan dalam daerah tersebut. Sumur resapan dan biopori banyak digunakan antara lain di Bali (Gede, 2017) dan Jawa Barat (Ridwan, 2014). Penggunaannya selain untuk mengatasi permasalahan banjir, juga untuk peningkatan infiltrasi air tanah. Namun karena debit resapan kecil, maka sumur resapan dan biopori kurang efektif untuk mengatasi permasalahan banjir (Joko, 2014; Hari, 2019; dan Edi, 2014). Dengan demikian diperlukan inovasi sumur resapan yang memiliki daya resap yang cukup besar (Edy, 2018). Penggunaan sumur untuk pengisian air tanah telah dilakukan oleh beberapa negara antara lain di Lahore (Fiaz, et.al, 2019). Exploitasi air tanah berlebihan di India menyebabkan permukaan air tanah menurun dan terjadinya intrusi air laut. Untuk mengatasi permasalahan tersebut dilakukan pengisian air tanah di beberapa wilayah dengan menggunakan sumur resapan (Amarty, 2010).

Pipa resapan merupakan bangunan yang berfungsi untuk meresapkan air permukaan ke dalam tanah dan dipasang secara horisontal. Peresapan air ke dalam tanah sebanding dengan tinggi tekanan hidrolis, permeabilitas tanah, dan faktor bentuk. Pipa resapan horisontal memiliki dimensi yang tidak dibatasi oleh kedalaman air tanah, sehingga faktor bentuk menjadi besar dan akan meningkatkan kapasitas resapan. Bangunan resapan dengan dinding berlubang memiliki daya resap air yang lebih besar dibandingkan tanpa lubang untuk dimensi yang sama (Edy et.al. 2012). Diharapkan pipa resapan ini menjadi alternatif solusi untuk meningkatkan infiltrasi air dan menjaga kelestariannya.

Debit aliran bebas yang melalui lubang kecil menurut Triatmojo (1996) dinyatakan dengan persamaan:

$$
Q=C_{d} \cdot a \sqrt{2 \cdot g \cdot H}
$$

Sedangkan debit aliran tenggelam dinyatakan dengan persamaan:

Keterangan:

$$
Q=C_{d} \cdot a \sqrt{2 \cdot g \cdot\left(H_{2}-H_{1}\right)}
$$

$$
\begin{array}{ll}
\mathrm{Cd} & : \text { koefisien debit } \\
\mathrm{a} & : \text { luas bukaan lubang }\left(\mathrm{m}^{2}\right) \\
\mathrm{g} & : \text { percepatan grafitasi }\left(\mathrm{m} / \mathrm{dt}^{2}\right) \\
\mathrm{H} & : \text { tinggi tekanan }(\mathrm{m}) \\
\mathrm{Q} & : \text { debit aliran }\left(\mathrm{m}^{3} / \mathrm{dt}\right)
\end{array}
$$


Menurut Triatmojo (1996), koefisien debit Cd harus ditentukan dengan percobaan. Dengan demikian rumus tersebut dapat dijadikan dasar dalamperhitungan debit infiltrasi pipa resapan.

Menurut Sriyono (2013) Persamaan (1) dapat digunakan untuk menghitung debit aliran melalui pipa berpori sehingga dapat dituliskan dengan Persamaan (3).

$$
Q=C_{d} A_{f} \sqrt{2 \cdot g \cdot H}
$$

Keterangan:

$$
\begin{aligned}
& \text { Cd : koefisien debit } \\
& A_{f} \text { : luas lubang }\left(\mathrm{m}^{2}\right) \\
& g \text { : percepatan grafitasi }\left(\mathrm{m} / \mathrm{dt}^{2}\right) \\
& \mathrm{H} \text { : tinggi tekanan (m) } \\
& \text { Q : debit aliran ( } \left.\mathrm{m}^{3} / \mathrm{dt}\right)
\end{aligned}
$$

Harga Cd pada persamaan di atas menurut Sriyono (2013) merupakan fungsi beberapa variable seperti pada Persamaan (4)

$$
C_{d}=f\left(\frac{K}{\sqrt{g \cdot H}}, \frac{A_{f}}{A}\right)
$$

Keterangan:

$$
\begin{array}{lll}
\mathrm{Cd} & : & \text { koefisien debit } \\
\mathrm{A}_{\mathrm{f}} & : & \text { luas seluruh lubang }\left(\mathrm{m}^{2}\right) \\
\mathrm{A} & : \text { luas dinding pipa }\left(\mathrm{m}^{2}\right) \\
\mathrm{A}_{\mathrm{f}} / \mathrm{A}: & \text { rasio lubang dinding } \\
\mathrm{g} & : \text { percepatan grafitasi }\left(\mathrm{m} / \mathrm{dt}^{2}\right) \\
\mathrm{K} & : \text { permeabilitas tanah }(\mathrm{m} / \mathrm{dt}) \\
\mathrm{H} & : \text { tinggi tekanan }(\mathrm{m}) \\
\mathrm{Q} & : & \text { debit aliran }\left(\mathrm{m}^{3} / \mathrm{dt}\right)
\end{array}
$$

Sriyono mengunakan Persamaan (4) untuk perhitungan koefisien debit pengambilan air dengan pipa berpori. Penggunaannya untuk pipa resapan perlu dilakukan penelitian.

Hidrolika pipa berlubang sangat rumit (van Schilfgaarde et.al, 1974), maka diperlukan pengamatan empiris debit pipa resapan.

\section{METODOLOGI}

Disiapkan pipa diameter $10 \mathrm{~cm}$ dengan dinding berlubang diameter $10 \mathrm{~mm}$ berjarak $5,7 \mathrm{~cm}$ sebanyak 4 baris atau rasio lubang dinding 0,028. Panjang 7 meter dibagi menjadi 6 segmen dengan panjang 2 meter dan selanjutnya disambung dengan pipa 1 meter. Ujung pipa 2 meter dihubungkan dengan knee dan disambungkan vertikal pipa diameter yang sama tanpa dilubangi dindingnya dengan panjang 1 meter. Lubang dinding masing-masing segmen ditutup dengan lakban dan dihubungkan dengan tali sampai ujung lubang pipa vertikal. Selanjutnya pipa tersebut dipasang di dalam tanah 
secara horisontal dengan ujung vertikal kurang lebih $20 \mathrm{~cm}$ di atas permukaan tanah. Pengujian pipa resapan dilakukan untuk panjang 2 meter, 3 meter, 4 meter, 5 meter, 6 meter, dan 7 meter dengan cara melepas lakban yang terhubung tali pada ujung pipa. Pengujian resapan untuk masing-masing panjang dilakukan dengan mengisi pipa sampai penuh selanjutnya dibiarkan terjadi penurunan muka air yang tercatat oleh alat pengukur kedalaman air tiap 5 detik. Dengan demikian debit resapan dapat dihitung dengan menghitung volume penurunan dengan waktu resapan.

Langkah-langkah penelitian beriukutnya dapat dilihat pada Gambar 1.

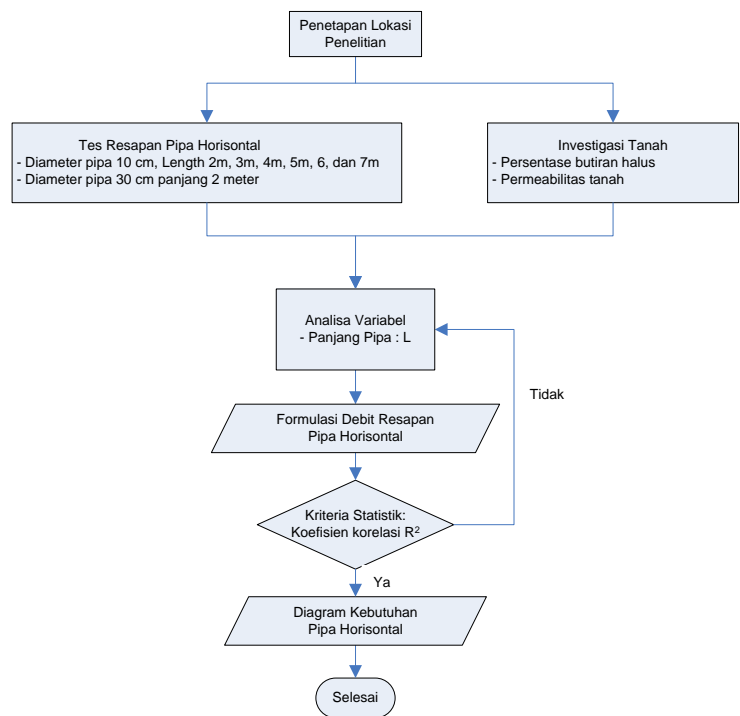

Gambar 1. Diagram Alir Metoda Penelitian

\section{HASIL DAN PEMBAHASAN}

Karakteristik tanah di lokasi penelitian dapat dlihat pada Tabel 1 berikut ini.

Tabel 1. Gradasi Tanah

\begin{tabular}{|c|l|c|c|}
\hline No. & Butiran Tanah & Satuan & $\begin{array}{c}\text { Hasil } \\
\text { Pengukuran }\end{array}$ \\
\hline 1. & Kerikil & $\%$ & 0.42 \\
\hline 2. & Pasir Kasar & $\%$ & 3.18 \\
\hline 3. & Pasir halus & $\%$ & 9.56 \\
\hline 4. & Lanau & $\%$ & 67.84 \\
\hline 5. & Lempung & $\%$ & 19.00 \\
\hline
\end{tabular}


Prosentase lanau dan lempung $86,84 \%$ tergolong tanah berbutir halus dan menurut klasifikasi segitiga tekstur tanah AASHTO tergolong tanah clay. Permeabilitas tanah sebesar $7.09 \times 10^{-6} \mathrm{~cm} /$ detik.

Dengan menggunakan program NCSS 12 persamaan diperoleh persamaan regresi untuk masing-masing panjang pipa dengan bentuk umum :

$$
\mathrm{Q}=\mathrm{A} \cdot \mathrm{H}^{\mathrm{B}}
$$

Keterangan:

$$
\begin{array}{ll}
\mathrm{H} & =\text { tinggi tekan air }(\mathrm{cm}) \\
\mathrm{A} \text { dan } \mathrm{B} & =\text { Konstanta } \\
\mathrm{Q} & =\text { debit resapan untuk tinggi tekan air } \mathrm{H}\left(\mathrm{cm}^{3} / \mathrm{dt}\right)
\end{array}
$$

Koefisien korelasi $\left(\mathrm{R}^{2}\right)$ untuk keenam panjang pipa diameter $10 \mathrm{~cm}$ dan rasio lubang terhadap luas dinding 0,028 dapat dilihat pada Tabel 2 .

Tabel 2. Koefisien korelasi dan konstanta persamaan regresi

\begin{tabular}{|c|c|c|c|c|}
\hline No. & $\begin{array}{c}\text { Panjang } \\
\text { Pipa }\end{array}$ & $\begin{array}{c}\text { Koefisien } \\
\text { Korelasi }\left(\mathrm{R}^{2}\right)\end{array}$ & $\begin{array}{c}\text { Konstanta } \\
\mathrm{A}\end{array}$ & $\begin{array}{c}\text { Konstanta } \\
\mathrm{B}\end{array}$ \\
\hline 1. & 7 meter & 0,80359 & 0,42523 & 1,64606 \\
\hline 2. & 6 meter & 0,89581 & 0,11855 & 1,95320 \\
\hline 3. & 5 meter & 0,90207 & 0,06827 & 1,97528 \\
\hline 4. & 4 meter & 0,90227 & 0,10692 & 1,83356 \\
\hline 5. & 3 meter & 0,81617 & 0,09084 & 1,81765 \\
\hline 6. & 2 meter & 0,88567 & 0,12669 & 1,66420 \\
\hline
\end{tabular}

Maka menurut persamaan (8), koefisien debit (Cd) dan luas lubang (Af) masuk ke dalam konstanta A sedangkan konstanta B merupakan pangkat dari variabel tinggi tekanan air $(\mathrm{H})$.

Apabila variabel panjang dimasukkan didapat persamaan umum untuk diameter pipa $10 \mathrm{~cm}$ :

Keterangan :

$$
\mathrm{Q}=0.000495 \times \mathrm{L}^{0.913} \times \mathrm{H}^{1,809}
$$

$$
\begin{array}{ll}
\mathrm{H} & =\text { tinggi tekanan air }(\mathrm{cm}) \\
\mathrm{L} & =\text { Panjang pipa }(\mathrm{cm}) \\
\mathrm{Q} & =\text { debit resapan untuk tinggi tekanan air } \mathrm{H}\left(\mathrm{cm}^{3} / \mathrm{dt}\right)
\end{array}
$$

Koefisien korelasi $\left(R^{2}\right)$ persamaan regresi diatas sebesar 0.8421 yang berarti cukup baik. Dengan pangkat variabel panjang (L) sebesar 0,913 untuk penyederhanaan debit resapan untuk diameter yang lain variabel panjang dapat dianggap sama dengan diameter $10 \mathrm{~cm}$. Grafik debit resapan untuk diameter $10 \mathrm{~cm}$ dengan panjang 2 meter sampai 7 meter dapat dilihat pada Gambar 2. 


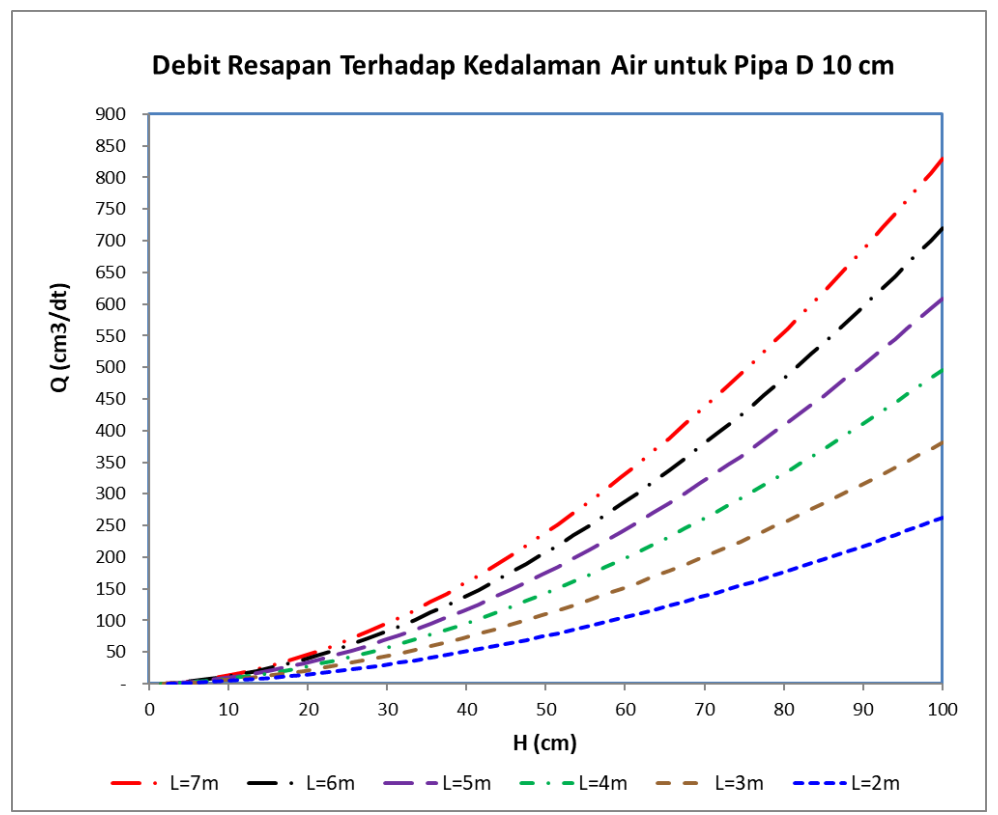

Gambar 2. Kurva Regresi Debit Resapan Pipa Horisontal Diameter $10 \mathrm{~cm}$ Sumber : Hasil Analisis Peneliti, 2019

Dengan rasio lubang dinding yang sama yaitu 0,028 hasil pengujian resapan pipa diameter $30 \mathrm{~cm}$ dan panjang 2 meter, menghasilkan debit resapan lebih besar sebagaimana dapat dilihat pada Gambar 3.

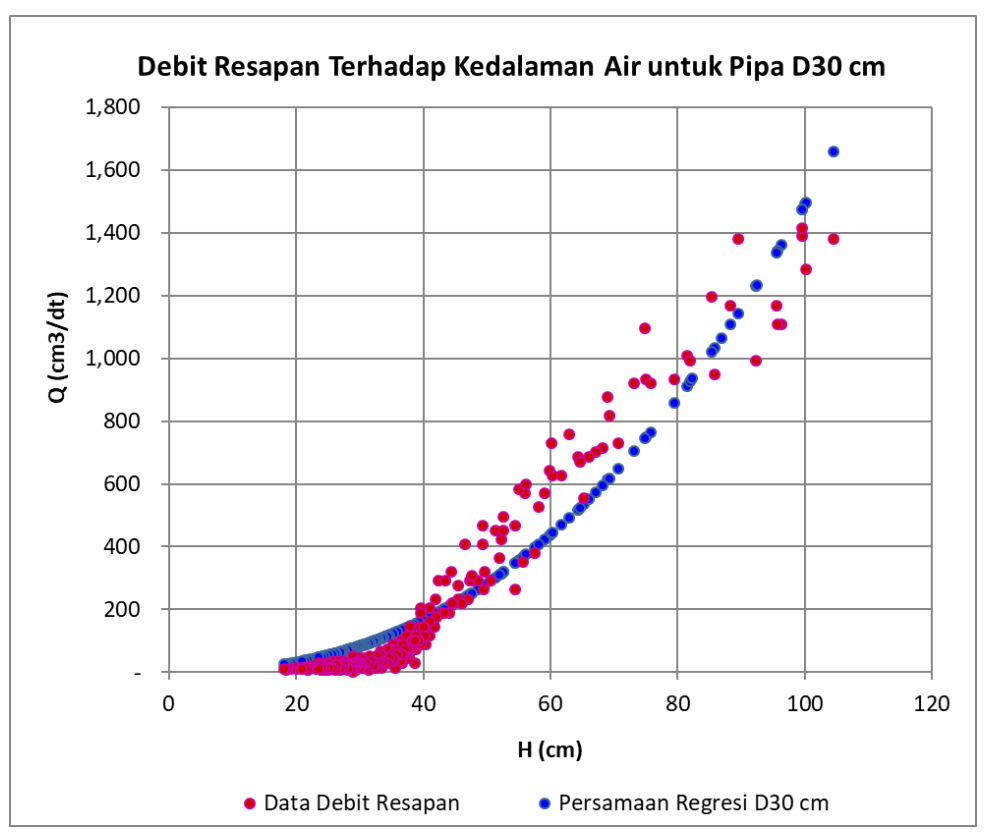

Gambar 3. Debit Resapan Pipa Horisontal Diameter $30 \mathrm{~cm}$ Panjang $2 \mathrm{~m}$ 
Sumber : Hasil Analisis Peneliti, 2019

Persamaan regresi untuk pipa diameter $30 \mathrm{~cm}$ dengan panjang $L$ meter rasio lubang 0,028 adalah sebagai berikut :

Keterangan :

$$
\mathrm{Q}=0.00019 \times \mathrm{L}^{0,913} \times \mathrm{H}^{2.3965}
$$

$\mathrm{H}=$ tinggi tekanan air $(\mathrm{cm})$

$\mathrm{L} \quad \quad=$ Panjang pipa $(\mathrm{cm})$

Q = debit resapan untuk tinggi tekanan air $\mathrm{H}\left(\mathrm{cm}^{3} / \mathrm{dt}\right)$

Debit banjir menurut persamaan rasional dinyatakan dengan rumus :

Keterangan :

$$
\mathrm{Q}=0,278 \times \mathrm{C} \times \mathrm{I} \times \mathrm{A}
$$

$\mathrm{C}=$ Koefisien pengaliran

I = Intensitas hujan ( $\mathrm{mm} / \mathrm{jam})$

A = Luas daerah aliran sungai $\left(\mathrm{km}^{2}\right)$

Q = debit banjir maksimum ( $\left.\mathrm{m}^{3} / \mathrm{dt}\right)$

Koefisien pengaliran merupakan merupakan nisbah jumlah air yang dapat melimpas dengan keseluruhan air hujan yang jatuh pada suatu daerah. Besarnya koefisen pengaliran tergantung pada penutup lahan di atas permukaan tanah.

Perubahan tataguna lahan akan menyebabkan perubahan koefisien pengaliran. Apabila perubahan koefisien pengaliran sebesar $\Delta \mathrm{C}$ maka akan terjadi perubahan debit sebesar $\Delta \mathrm{Q}$, sehingga persamaan (8) dapat ditulis menjadi :

$$
\Delta \mathrm{Q}=0,278 \times \Delta \mathrm{C} \times \mathrm{I} \times \mathrm{A}
$$

Keterangan :

$\Delta \mathrm{C}=$ Perubahan koefisien pengaliran

$\Delta \mathrm{Q}=$ Perubahan debit banjir maksimum $\left(\mathrm{m}^{3} / \mathrm{dt}\right)$

Perubahan tataguna lahan yang berakibat penurunan infiltrasi air tanah dan peningkatan debit banjir dapat dilakukan dengan pipa resapan.

Debit yang perlu diresapkan ke dalam tanah dengan pipa resapan dengan intensitas hujan I mm/jam, perubahan koefisien pengaliran $\Delta \mathrm{C}$ dan luas DAS $\mathrm{A} \mathrm{km}^{2}$ dapat dilihat pada Tabel 3. $\Delta$ C.A adalah perkalian antara perubahan koefisien pengaliran dengan luas DAS $\left(\mathrm{km}^{2}\right)$ untuk kemudahan perhitungan.

Tabel 3. Debit yang perlu diresapkan akibat perubahan tataguna lahan 


\begin{tabular}{|c|c|c|c|c|c|c|c|c|}
\hline \multirow{2}{*}{$\begin{array}{l}\text { Intensita } \\
\text { s Hujan I } \\
\text { (mm/jam } \\
\text { ) }\end{array}$} & \multicolumn{8}{|c|}{$\begin{array}{l}\text { Debit yang diresapkan akibat perubahan koefisien } \\
\text { Pengaliran }\left(\mathrm{m}^{3} / \mathrm{dt}\right)\end{array}$} \\
\hline & $\begin{array}{l}\square \mathrm{C} . \mathrm{A} \\
\square \square \square\end{array}$ & $\begin{array}{l}\mathrm{C} . \mathrm{A} \\
0.50\end{array}$ & $\begin{array}{l}\mathrm{C} . \mathrm{A} \\
1.00\end{array}$ & $\begin{array}{l}\mathrm{C} . \mathrm{A} \\
1.50\end{array}$ & $\begin{array}{l}\square \mathrm{C} . \mathrm{A} \\
2.00\end{array}$ & $\begin{array}{l}\mathrm{C} . \mathrm{A} \\
2.50\end{array}$ & $\begin{array}{l}\square \mathrm{C} . \mathrm{A} \\
3.00\end{array}$ & $\begin{array}{l}\text { C.A } \\
3.50\end{array}$ \\
\hline 0 & 0.00 & 0.00 & 0.00 & 0.00 & 0.00 & 0.00 & 0.00 & 0.00 \\
\hline 25 & 0.70 & 3.48 & 6.95 & $\begin{array}{r}0.4 \\
3\end{array}$ & .9 & $\begin{array}{r}7.3 \\
8\end{array}$ & 0.8 & $\begin{array}{r}24.3 \\
3\end{array}$ \\
\hline 50 & 1.39 & 6.95 & $\begin{array}{r}3.9 \\
0\end{array}$ & $\begin{array}{r}20.8 \\
5\end{array}$ & $\begin{array}{r}27.8 \\
0\end{array}$ & $\begin{array}{r}34.7 \\
5\end{array}$ & $\begin{array}{r}41.7 \\
0\end{array}$ & $\begin{array}{r}48.6 \\
5\end{array}$ \\
\hline 75 & 2.09 & $\begin{array}{r}10.4 \\
3\end{array}$ & $\begin{array}{r}20.8 \\
5\end{array}$ & $\begin{array}{r}31.2 \\
8\end{array}$ & $\begin{array}{r}1.7 \\
0\end{array}$ & $\begin{array}{r}52.1 \\
3\end{array}$ & $\begin{array}{r}2.5 \\
5\end{array}$ & $\begin{array}{r}72.9 \\
8\end{array}$ \\
\hline 100 & 2.78 & $\begin{array}{r}13.9 \\
0\end{array}$ & $\begin{array}{r}27.8 \\
0\end{array}$ & $\begin{array}{r}41.7 \\
0\end{array}$ & $\begin{array}{r}5.6 \\
0\end{array}$ & $\begin{array}{r}69.5 \\
0\end{array}$ & $\begin{array}{r}3.4 \\
0\end{array}$ & $\begin{array}{r}97.3 \\
0\end{array}$ \\
\hline 125 & 3.48 & $\begin{array}{r}17.3 \\
8\end{array}$ & $\begin{array}{r}34.7 \\
5\end{array}$ & $\begin{array}{r}2.1 \\
3\end{array}$ & $\begin{array}{r}9.5 \\
0\end{array}$ & $\begin{array}{r}86.8 \\
8\end{array}$ & $\begin{array}{r}104 . \\
25\end{array}$ & $\begin{array}{r}121 . \\
63\end{array}$ \\
\hline 150 & 4.17 & $\begin{array}{r}20.8 \\
5\end{array}$ & $\begin{array}{r}41.7 \\
0\end{array}$ & $\begin{array}{r}2.5 \\
5\end{array}$ & $\begin{array}{r}83.4 \\
0\end{array}$ & $\begin{array}{r}104 . \\
25\end{array}$ & $\begin{array}{r}125 . \\
10\end{array}$ & $\begin{array}{r}145 . \\
95\end{array}$ \\
\hline 175 & 4.87 & $\begin{array}{r}24.3 \\
3\end{array}$ & $\begin{array}{r}48.6 \\
5\end{array}$ & $\begin{array}{r}72.9 \\
8\end{array}$ & $\begin{array}{r}7.3 \\
0\end{array}$ & $\begin{array}{r}121 . \\
63\end{array}$ & $\begin{array}{r}145 . \\
95\end{array}$ & $\begin{array}{r}170 . \\
28\end{array}$ \\
\hline 200 & 5.56 & $\begin{array}{r}27.8 \\
0\end{array}$ & $\begin{array}{r}55.6 \\
0\end{array}$ & $\begin{array}{r}3.4 \\
0\end{array}$ & $\begin{array}{r}111 . \\
20\end{array}$ & $\begin{array}{r}139 . \\
00\end{array}$ & $\begin{array}{r}166 . \\
80\end{array}$ & $\begin{array}{r}194 . \\
60\end{array}$ \\
\hline 225 & 6.26 & $\begin{array}{r}31.2 \\
8 \\
\end{array}$ & $\begin{array}{r}62.5 \\
5\end{array}$ & $\begin{array}{r}3.8 \\
3\end{array}$ & $\begin{array}{r}125 . \\
10\end{array}$ & $\begin{array}{r}156 . \\
38\end{array}$ & $\begin{array}{r}187 . \\
65\end{array}$ & $\begin{array}{r}218 . \\
93\end{array}$ \\
\hline 257 & 7.14 & $\begin{array}{r}35.7 \\
1\end{array}$ & $\begin{array}{r}71.4 \\
3\end{array}$ & $\begin{array}{r}107 . \\
14\end{array}$ & $\begin{array}{r}142 . \\
86\end{array}$ & $\begin{array}{r}178 . \\
57\end{array}$ & $\begin{array}{r}214 . \\
29\end{array}$ & $\begin{array}{r}250 . \\
00\end{array}$ \\
\hline
\end{tabular}

(Sumber : Hasil Analisis Peneliti, 2019)

Selain dengan menggunakan tabel di atas perhitungan debit yang perlu diresapkan juga dapat dilakukan secara manual dengan menggunakan persamaan (9).

Kebutuhan pipa resapan didapat dengan membagi debit yang perlu diresapkan dengan kapasitas debit sebuah pipa. Dengan menggunakan persamaan (7) untuk diameter pipa resapan $30 \mathrm{~cm}$, panjang $400 \mathrm{~cm}$, rasio lubang dinding pipa 0,028, dan diasumsikan tinggi tekanan air $100 \mathrm{~cm}$, maka debit resapan tiap pipa sebesar $0.0028 \mathrm{~m}^{3} / \mathrm{dt}$. Untuk lebih mudahnya kebutuhan pipa resapan untuk $\Delta$ C.A 0.10 sampai 3.50 dan intensitas hujan $0 \mathrm{~mm} / \mathrm{jam}$ sampai $257 \mathrm{~mm} / \mathrm{jam}$ dapat menggunakan grafik pada Gambar 3. 


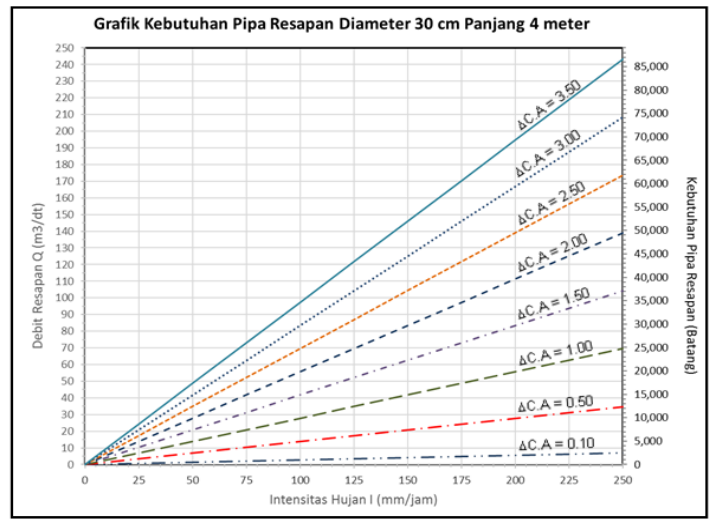

Gambar 3. Kebutuhan Pipa Resapan Horisontal Diameter $30 \mathrm{~cm}$ Panjang $4 \mathrm{~m}$ Sumber : Hasil Analisis Peneliti, 2019

Untuk intensitas hujan, perubahan koefisien pengaliran, maupun luas lahan yang tidak sesuai dengan tabel di atas dapat dilakukan interpolasi linear.

\section{KESIMPULAN}

Pipa resapan horisontal dengan dinding berlubang cukup efektif untuk peningkatan infiltrasi air tanah dan penurunan debit banjir. Kebutuhan jumlah pipa resapan dengan diameter $30 \mathrm{~cm}$, panjang 4 meter, rasio lubang dinding 0.028 dapat menggunakan grafik. Penelitian ini terbatas untuk tanah dengan permeabilitas sebesar $7,087 \times 10^{-6} \mathrm{~cm} /$ detik atau jenis tanah clay. Dengan demikian perlu dilakukan pengembangan penelitian pipa resapan horizontal dengan diameter yang lain dan jenis tanah berbeda.

\section{DAFTAR PUSTAKA}

Amarty, K.B., 2010, "Artificial Ground Water Recharge With a Special Reference to India", IJRRAS 4 (2), August 2010.

Edi, P.U. (2014). "Peneliti LIPI: Biopori Kurang Efektif Cegah Banjir", http://lipi.go.id/berita/single/Peneliti-LIPI-Biopori-Kurang-Efektif-CegahBanjir/9799

Edy, S., Bambang, P., Diah, S.B. (2012). Sumur Resapan Sederhana dengan Dinding Berlubang, Laporan Penelitian LPPM Universitas Semarang.

Edy, S., Suripin, Suharyanto. (2018). Field performance of shallow recharge well, MATEC Web of Conferences 195, 05006 (2018), ICRMCE 2018, p. 5, https://doi.org/10.1051/matecconf/201819505006

Fiaz, H., Riaz, H., Ray-Shyan Wu, dan Tanveer, A. (2019). "Rainwater Harvesting Potential and Utilization for Artificial Recharge of Groundwater Using Recharge Wells", Processes 2019, 7, 623; doi:10.3390/pr7090623. 
Forchheimer (1930) "Hydraulik”, Leipzig, Berlin, B.G. Teubner.

Gede, S. (2017) "Cara ini Lebih Efektif Menyimpan Air ke Tanah Dibanding Biopori", https://www.mongabay.co.id/2017/03/07/cara-ini-lebih-efektifmenyimpan-air-ke-tanah-dibanding-biopori/.

Hari, S. (2019) "Kementerian PUPR: Sumur Resapan Bagus, Cuma Banjir Tak Mudah Selesai", https://megapolitan.kompas.com/read /2019/03/21/15245161/kementerian-pupr-sumur-resapan-bagus-cumabaniir-tak-mudah-selesai

Joko, K. (2014) " Menteri PU: Sumur Resapan Pemprov DKI Tidak Efektif", https://news.okezone.com/read/2014/01/15/500/926703/menteri-pusumur-resapan-pemprov-dki-tidak-efektif.

Rahman, H. (2008). "Aplikasi Water Balance Model untuk manajemen air hujan perkotaan: Studi Kasus pada Sub-DAS Sugutamu”, Universitas Indonesia, hal. 10

Ridwan, K. (2014). "Peneliti LIPI: Biopori Kurang Efektif Cegah Banjir", http://lipi.go.id/berita/single/Peneliti-LIPI-Biopori-Kurang-Efektif-CegahBanjir/9799.

Sriyono. (2013) "Kajian Hitungan Debit Aliran Melalui Pipa Berpori Terhadap Kapasitas: Media Porous, Pori Pipa, dan Orifice", Jurnal Teknik Vol.3 No.1/APRIL 2013, ISSN 2088.3676.

Triatmojo B. (1996). Hidrolika I, Beta Offset, Yogyakarta.

van Schilfgaarde, J., ed. (1974). "Drainage for Agriculture", Agronomy Series No. 17, American Society of Agronomy, Madison, WI. 